\title{
Design and Fabrication of Multipurpose Mechanical Machine
}

\author{
Shubhamkar Dhoble ${ }^{1}$, Ghanshyam Kannake ${ }^{2}$, Kunal Nannaware ${ }^{3}$, Krunal Telrandhe ${ }^{4}$, \\ Prof. Ajay Bonde \\ 1,2,3,4,5 Department of Mechanical Engineering, Yeshwantrao Chavan college of engineering, Nagpur
}

Received on: 18 November,2020, Revised on: 15 December,2020, Published on: 29 December,2020

\begin{abstract}
This project emphasis on design and fabrication of multipurpose machine. The project aims at designing and developing a multipurpose machine tool which is capable of performing multiple tasks simultaneously. The fundamental functions of machine tools are to transform the raw materials with given mechanical properties to the finished parts with required geometry, dimensions and surface quality. As the demands are increasing to produce parts with higher quality at reduced cost, the machine tools are required to have higher machining accuracy and speed. In this project we have a proposed a machine which can perform operations like drilling, cutting and grinding simultaneously which implies that industrialist have not to pay for machine performing above tasks individually for operating operation simultaneously.
\end{abstract}

\section{I- INTRODUCTION}

$\mathbf{T}$ his project emphasis on design and fabrication of multipurpose machine. The project aims at designing and developing a multipurpose machine tool which is capable of performing multiple tasks simultaneously. The fundamental functions of machine tools are to transform the raw materials with given mechanical properties to the finished parts with required geometry, dimensions and surface quality. As the demands are increasing to produce parts with higher quality at reduced cost, the machine tools are required to have higher machining accuracy and speed. In this project we have a proposed a machine which can perform operations like drilling, cutting and grinding simultaneously which implies that industrialist have not to pay for machine performing above tasks individually for operating operation simultaneously.

\section{II- PROBLEM IDENTIFICATION}

1. To make a machine which can do a single operation as well as multiple operations at a time?

2. Propose a machine with less mechanism and high power delivery.

3. The machine can perform drilling, cutting, grinding operation.

Existing method

The existing system is completely a mechanical based project. In the prior technology, they perform operations such as drilling, grinding and cutting was running at same time. Our upgrades are that we are using coupling for operating single operation at a time and also multiple operations at a time. 


\section{International Journal of Innovations in Engineering and Science, www.ijies.net}

\section{III- CONSTRUCTION AND WORKING PRINCIPLE}

Construction -The basic components of a multi-purpose mechanical machine are single phase induction motor, V-belt and pulley, bearings, drill chuck, pulleys, grinding wheel, and saw cutter with frame. The motor which mounted at bottom frame where the shaft of motor is connected with the small pulley and through this power is transmitted from smaller pulley to the bigger pulley which attached at top frame with the help of $\mathrm{V}$ belts. The bigger pulley rotates the shaft which are mounted on the top frame. Both end of the shaft is connected with the coupling which is use to perform drilling and cutting operations. The drilling shaft consists of drill chuck at the end to hold the drill bit of varying sizes. Here coupling mechanism is connected on both which is used for engaging and disengaging of operations where, at one time only one operation can perform with the help of coupling, so from this the power which are consume by other operations are focused only on one particular operation from that we can achieve high power delivery and better performance also. Now the shaft1 which are mounted on top frame consist two pulleys i.e.; big pulley and small pulley. With the help of $\mathrm{V}$ belt drive the small pulley which is consist on shaft 1 can transfer the power to bigger pulley which is mounted on shaft 2 where it is located at the top frame. So the shaft 2 having an operation like grinding wheels for surface finish for bringing the component to desired shape and size.

\section{- Couplings}

Couplings are mechanical elements that coupled two shaft which enables motion to be transferred from one element to another.

\section{- Types of Coupling}

1. Rigid Coupling.

2. Flexible Coupling.

In this mechanism we are using Flexible Coupling it is use to connect both lateral and angular with aligned shaft. Similar construction as rigid coupling, rubber bushes are inserted in coupled part. To overcome the problems arising due to misalignment "Bush Pin Type Flexible Coupling" is used. A flexible coupling consists a flexible like a rubber bush between the driving and driven flanges. This flexible bush not only accommodated the misalignment but also sustain vibration and shock.

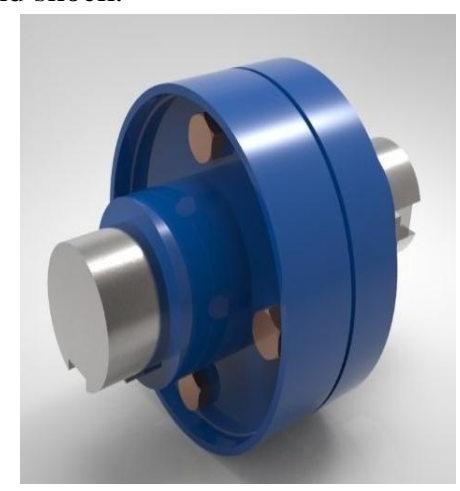

\section{IV-WORKING PRINCIPLE}

The arrangement has electrical motor, coupling, bearing, shaft, cutting, drilling and grinding set up. The power is transmitted to the first shaft from the electrical motor which is driven by electrical current. The grinding wheel is attached at the one end of the shaft and drilling operation takes place at the other end of the shaft. Cutting action takes place at the second shaft which is driven by the first shaft with the help of belt and pulley arrangement.

Coupling is used for the engagement and disengagement purpose. We can perform any of the three operations or all the three operations as per our requirement.

\section{V- MATERIALS / TOOLS REQUIRED}

1. In-House Facilities

- Cad designing software

- Thermal simulation

- Fabrication lab

\section{External Facilities}

- Welding and other machining process.

\section{VI- BASIC STRUCTURE OF MACHINE}

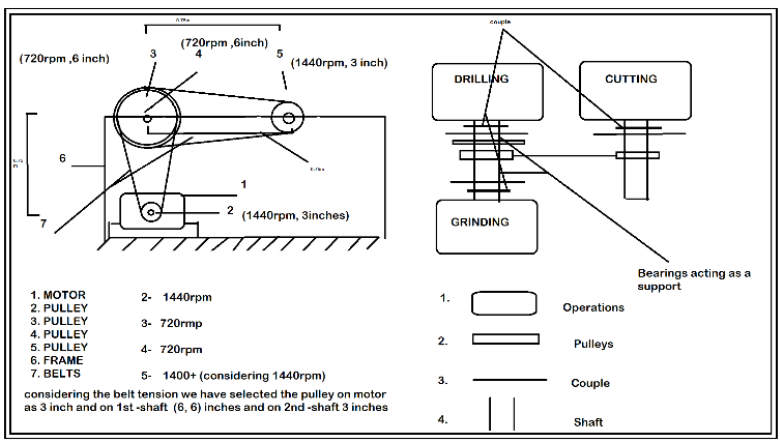




\section{International Journal of Innovations in Engineering and Science, www.ijies.net}

\section{VII- ADVANTAGES \& LIMITATIONS}

\section{Advantages}

- Initial \& maintenance cost is less.

- It is very useful for small scale industries.

- Easy replacement and installation of various parts

- Skill worker not required to drive the system self-propel.

\section{Limitations}

- We cannot perform single operation at a time.

- Safety of operator is less.

- Maintenance high.

\section{VIII-FUTURE SCOPE}

- Replacement of multiple machines and compact it in single operated machine.

- Can be used in small and medium scale industries for multiple operations.

\section{IX-CONCLUSIONS}

The project was developed with the help of literature and conference papers along with different books related to the project. The innovation made within this machine has immense scope in the coming future. With this work we were able to gain lot of knowledge along with great open ideas subjected to it. The project is done based on calculated values and feasible market availability. The machine does able to work all the given operations and functions well while performing operations. The machine is efficient which will reduce the time and energy required as well as man power.

\section{REFERENCES}

[1] M. 1. Machine Selection Rules in a Dynamic Job Shop; Names: V. Subramanian, G. K. Lee, T. Ramesh, G. S. Hong and Y. S. Wong. Department of Mechanical and Production Engineering, National University of Singapore, Singapore International Journal Adv. Manufacture Technology (2000) 16:9029082000 Springer-Verlag London Limited.

[2] Multi-functional machine tool; Name: T. Mariachi Department of Industrial and Systems engineering, Setsunan University, Neyagawa, Japan CIRP Annals Manufacturing Technology 2008 CIRP.
[3] Homokinetic Shaft- Coupling Mechanism Via Double Schoenflies motion Generetors .Names: Chung-Chin and Lee Jacques M. Hervé ASME 2014 International Design Engineering Technical Conferences August 17 20, 2014, Buffalo, New York, USA

[4] Vibration influence on a drilling machine Names: Lushnikov R.E., Shvagrukova E.V.2014 International Conference on Mechanical Engineering, Automation and Control Systems (MEACS), Tomsk, Russia 2014 IEEE 